\title{
REPRESENTAÇÃO DE IDENTIDADE EM REDES SOCIAIS DE NICHO: ESTUDO COM APLICAÇÃO DE TÉCNICAS QUALITATIVAS
}

\author{
IDENTITY REPRESENTATIONS ON NICHE SOCIAL NETWORKS: \\ STUDY WITH QUALITATIVE TECHNIQUES
}

\author{
SANTOS, Robson, D.Sc. \\ Doutor em Design \\ e-mail: interfaceando@gmail.com
}

\begin{abstract}
RESUMO
Este artigo trata de um tópico subjacente de estudo sobre a cena underground é a existência de redes sociais de nicho - em particular as destinadas à comunidade fetichista. Apresenta-se um processo de contínuo de pesquisa, que possa produzir dados relevantes e ser introduzido no fluxo de projetos de UX. A abordagem qualitativa e imersiva permite conhecer da realidade de determinado grupo, amparada por técnicas de investigação das ciências sociais e humanas.
\end{abstract}

Palavras-chave: Metodologia, Experiência do Usuário, Redes Sociais, Identidade.

\begin{abstract}
This paper discuss a specific topic from a broader study about the underground scene and the existence of niche social networks - particularly those ones dedicated to the fetish community. The main goal is to introduce a continuous research process, due to produce relevant data that can be applyed in the UX project flow. The immersive qualitative approach allows us to better understand the reallity of a specific group, supported by research techniques from the social and human sciences.
\end{abstract}

Keywords: Methodology, User Experience, Social Networks, Identity.

\section{INTRODUÇÃO}

O usuário brasileiro tem adotado com considerável rapidez os websites de redes sociais. Se retomarmos aos anos de 1990, certamente hemos de lembrar a majoritária presença de usuários brasileiros no Orkut. Ainda hoje são feitas projeções de crescimento do engajamento em redes sociais no Brasil. Se considerarmos nossas próprias experiências com as plataformas mais conhecidas (Facebook, Instagram), fica relativamente fácil verificar a quantidade de 
pessoas que nos enviam solicitações de "amizade" a cada dia. Um aspecto que também deve ser considerado é a existência de perfis fora do padrão de normalidade na rede social Facebook. Em 2012 a empresa divulgou a informação de que cerca de $8.7 \%$ de seus usuários são compostos por perfis duplicados (4.8\%), mal clasificados (2.4\%) e indesejáveis (1.5\%), de acordo com notícia publicada site de notícia BBC News (2012).

Apesar de serem vistos como inadequados, segundo as regras da empresa, nem todo perfil duplicado ou com nome diferente do que consta no documento de identidade se refere a perfis falsos. Em ação recente, a empresa decidiu que todos os usuários deveriam utilizar seus nomes "reais", colocando em situação de exposição uma grande quantidade de performers, drag queens, transexuais e travestis. Os principais argumentos contra a decisão da empresa consideram que as personas online refletem suas atividades artísticas, que uma vez reveladas, poderiam colocar em risco suas vidas pessoais (Blue, 2014).

Isto nos traz à discussão sobre identidade em redes sociais de relacionamento. Sobre o termo identidade, Nóbrega (2010) destaca que "deixa de ser algo dado com o nascimento e passa a ser conceituada como algo em constante construção e transformação. Ela não se trata mais de uma coisa imposta, mas do produto de escolhas." Mais a frente, no mesmo artigo, a autora reforça que:

"Toda construção identitária é comunicada ao mundo e aos outros sob a forma de representação. Ela é um projeto a ser criado e que deve também ser reafirmado para se legitimar.

Os usuários das redes virtuais de relacionamento se utilizam da internet como ferramenta para construir suas identidades. Tais redes sociais estabelecem-se assim como local por excelência onde as identidades são reafirmadas por meio de símbolos."

Pearson (2009), ao traz a ideia de performance (atuação), como elemento caractístico de nossas identidades online. A autora reflete que "users manipulate communicative codes, with varying degrees of skill and dexterity, to create not only online selves, but also to create the staging and setting in which these selves exist".

Além das redes sociais mais populares, existem as redes sociais de nicho, com foco em determinado grupo ou determinado assunto. O tema deste artigo surgiu da imersão e da experiência pessoal no universo undeground paulistano. Considera-se underground a produção artística, cultural e de mídia feita de maneira independente e autônoma em relação aos canais de produção e divulgação largamente conhecido pelo mercado.

Gomes (2013), ao falar sobre a música underground destaca que é "(...) modo amador de produção musical assente em relações de cooperação voluntária: invisibilidade e anonimato dos agentes sociais; rituais e estilos de sociabilidade específicos, simbolizados através da prática musical."

Outro conceito importante é o de subsultura. Como coloca Kipper (2008):

"Subcultura pode significar uma 'parte de uma cultura' que possui um conjunto diferenciado de 'valores, crenças, normas e padrões de comportamento, portanto um modo de vida compartilhado por parte de uma população'. 
"Temos um cenário no qual a cultura das zonas urbanas industrializadas tende a perder características locais e a adotar características de uma cultura global economificada: a cultura da sociedade de consumo contemporânea. Neste contexto, depois da Segunda Guerra Mundial (1939-1945), começam a surgir algumas subculturas urbanas."

Bennett (1999) após seu estudo imersivo sobre dança urbana na zona de Newcastle, argumenta que "those groupings which have traditionally been theorised as coherent subcultures are better understood as a series of temporal gatherings characterised by fluid boundaries and floating memberships."

Conceito paralelo é o de "tribo", um grupo que compartilha de regras e de comportamentos que se unem "não [...] com o objectivo de se isolarem de tudo o que os rodeia, mas para reencontrarem com o objetivo de se reencontrarem com grupos de referência mais próximos de seus ideais". Pais e Blass (2004)

Bennett (op. cit), por sua vez, cita Maffesoli (1996) para falar do conceito de neo-tribes, que em, linhas gerais é tratado como fenômeno da pós modernidade em que pesa menos fazer parte de um grupo ou comunidade fixo, mas sim circular por diversas instâncias:

Barros (2007) destaca que "Ainda que a inadequação do termo subcultura possa ser reivindicada como legítima, é exatamente a sua ambivalência e plasticidade - independente da nomenclatura que assuma - que permite uma abordagem mais adequada das distinções identitárias de determinados grupos sociais na contemporaneidade."

Verifica-se portanto, a importância dos websites de redes sociais não só para a construção destas identidades, como também para encontrar pares e grupos com os quais os sujeitos possam identificar-se. Com as possibilidades tecnológicas, fatores de sociabilidade ganham dimensão, o que permite a cada um ser vários e alternar entre papéis com a velocidade do clique de mouse, ou de um toque na tela.

\section{FETICHES E FETICHISMOS}

Em suas origens, o termo fetiche remonta o desentendimento decorrente do choque de culturas entre os colonizadores portugueses do século XVI ao se defrontarem com práticas religiosas (Voli, 2006). Para os termos fetiche e fetichismo atualmente há três aplicações para:

- religião: remonta à origem do termo, descrevendo objetos e práticas em que elementos inanimados podem ser encantados e atuar como amuletos; também podem ser utilizados em memória de alguma divindade ou entidade visível ou invisível;

- economia: Karl Marx elaborou o conceito de fetichismo da mercadoria, no qual trata da substituição da mão de obra e do esforço humano por seus resultados enquanto mercadorias produzidas; este conceito tem sido revisto, ao ponto de alguns intelectuais críticos do capitalismo destacarem que o ser humano em si é tratado como coisa, como objeto dentro do ciclo de produção;

- psicologia e psiquiatria: Freud elaborou o conceito ao tratar de determinadas fixações que pacientes apresentavam por objetos inanimados, que lhes causavam excitação sexual; de maneira geral, talvez seja esta a acepção mais popularmente conhecida do termo, e 
também possivelmente a mais sujeita a equívocos. Contra tais equívicos, ainda existentes na própria comunidade médica, Ogas (2012) argumenta: "the terms fetish and paraphilias marginalize and pathologize natural and healthy sexual interests. At the very least, clinical catalogs of paraphilias should be modified to more accurately reflect the true patterns of sexual interests in the population".

Fetiches, são, em linhas gerais, objetos inanimados (uma pedras, o valor da moeda, uma cintaliga) os quais exercem fascínio sobre determinadas pessoas ou grupos de pessoas. Como afirma Denis (1998): "Os objetos só podem adquirir significados a partir da intencionalidade humana". Tomando por base o trabalho de Voli (2006), este artigo leva em consideração a terceira das três aplicações do termo fetiche listadas acima e investiga a criação de identidades, bem como suas representações em websites de redes sociais.

\section{DESENVOLVIMENTO DO ESTUDO}

\subsection{Imersão e definição de tópicos de interesse}

Costa (1986) destaca que na pesquisa social "o principal instrumento de pesquisa é o próprio investigador", e que quando em campo, "observa os locais, os objetos e os símbolos, observa as pessoas, as actividades, os comportamentos, as interações verbais, as maneiras de fazer, de estar e de dizer, observa as situações, os ritmos, os acontecimentos. Participa, duma maneira ou doutra, no quotidiano desses contextos e dessas pessoas. Conversa com elas; por vezes entrevista-as mais formalmente. É frequente arranjar 'informantes privilegiados', interlocutores preferenciais com quem contacta mais intensamente ou de quem obtém informações sobre aspectos a que não pode ter acesso directo".

Tal processo foi vivido de maneira lenta e gradual, iniciado em novembro de 2013, para obter uma compreensão do universo de estudo e para encontrar tópicos que pudessem ser relevantes enquanto objetos de pesquisa. Em linhas gerais a entrada do pesquisador, seguiu-se o seguinte percurso:

1. busca por locais e eventos: visitas à Galeria do Rock, conversas informais para conhecer onde e com qual frequencia as festas aconteciam; além da busca na internet

2. construção de uma identidade, um alter ego, alinhado com a estética e com o estilo de vida do grupo

3. frequencia a festas e eventos: criação de perfil no Facebook, criação de imagem e identidade a ser usada na cena

4. utilização dos websites de redes sociais para traçar laços, e para obter informações sobre eventos e outras atividades

5. aproximação de algumas figuras chave (informantes privilegiados ou qualificados): produtores e promotores de festas, lojistas da Galeria do Rock, artistas e DJs

6. realização de atividades artísticas: ensaios fotográficos, exposições, performances

7. participação em eventos no Brasil e no exterior

Sobre a importância da imersão, cita-se a tradução feita por Siqueira e Lima (2005) do trabalho de Favret-Saada (1990), em que a autora argumenta em favor da imersão profunda, a ponto de 
ser afetada pela comunidade e por suas práticas, ao invés de fiar-se somente em revisões de literatura e de documentos e em informantes qualificados. Diz Favret-Saada: "É - parece-me urgente, reabilitar a velha 'sensibilidade', visto que estamos mais bem equipados para abordá-la do que os filósofos do século XVII".

Trazer estas perspectivas para os estudos de user experience implica uma preparação do pesquisador para além da coleta instrumental de dados, tornando-o um agente participativo das realidades investigadas, e colocando-o junto à comunidade que utiliza determinados produtos e serviços sob uma perspectiva "de dentro".

\subsection{Exemplos de websites de redes sociais de nicho}

Os websites destinados a fetichistas e similares valorizam o poder da fantasia e do imaginário, dando oportunidade para os participantes criarem alteregos e personas de maneira que lhes seja mais conveniente.

Ao serem perguntados se utilizam redes sociais dedicadas a fetiches e similares, $60 \%$ dos respondentes disseram "Sim". Ao responderem quais os mais acessados (pergunta com respostas múltiplas), dentre as 17 opções disponíveis, destacaram-se o Fetlife (30\%), BDSM Videos (14\%), Fetishes movies (9\%) e Kinky (9\%).

A rede Fetlife (fig. 1) possui abrangência mundial e conta com um crescente número de usuários brasileiros. Em 21 de janeiro de 2015 contavam-se com 32.860 membros que se declaravam residentes no Brasil (menos de 1\% do total de 3.544.364).

Existem redes ainda mais específicas, com rígidas regras para acesso e participação, havendo um processo para ser aceito, onde o candidato precisa demonstrar ser um membro ativo dentro da comunidade, ou em sua vida privada. É o caso do Breeches and Leather Uniform Fan Club BLUF, website de rede social dedicado a homens que tenham fetiche por couro, independentemente de orientação sexual, representada na imagem a seguir (fig. 2).

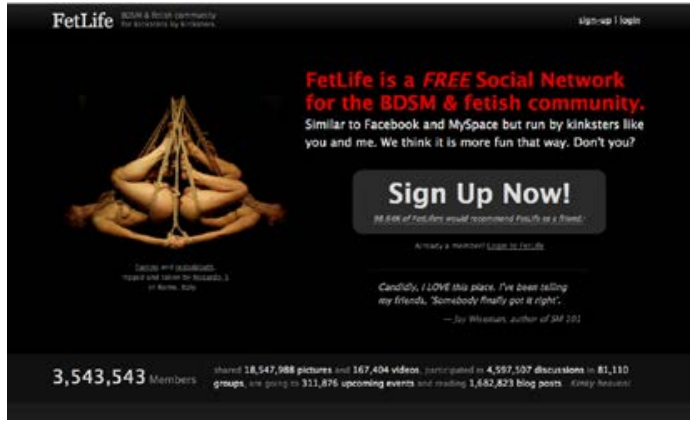

Figura 1 - Fetlife (www.fetlife.com)

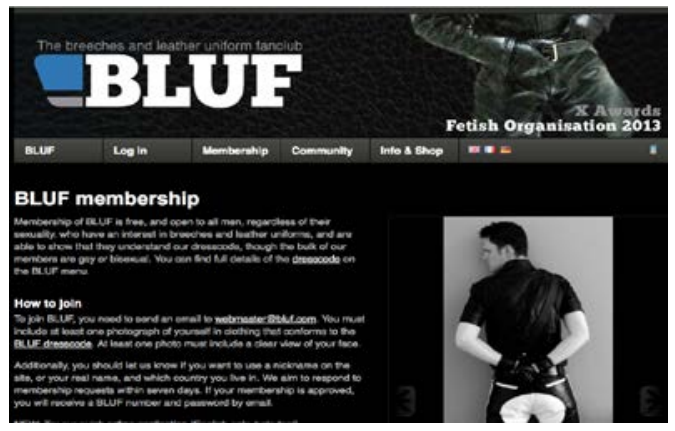

Figura 2 - BLUF (www.bluf.com)

Iniciativas como estas trazem a possibilidade de as pessoas participarem de grupos ou subgrupos onde possam construir, manter e exercitar suas identidades, de maneira teoricamente livre de julgamentos e livre da vigilância constante presente nos websites de redes sociais mainstream. 


\subsection{Questionários online}

O primeiro questionário foi mantido no ar de novembro de 2014 a janeiro de 2015. O questionário foi divulgado na página de perfil do Facebook e em grupos com assuntos relacionados a fetiche e BDSM. Também foi enviado o link para amigos e conhecidos por meio de mensagem instantânea, os quais poderiam compartilhar entre seus contatos.

Era composto por perguntas objetivas fechadas, cujas respostas eram de seleção única ou de múltipla seleção. O inquérito teve como foco pessoas residentes no Brasil e em Portugal. Uma vez que o campo da pesquisa inclui as cidades de São Paulo e Lisboa. Foram obtidas 340 respostas: $41 \%$ assumem o gênero feminino, 53\% o masculino. Havia as opções Transgênero (3\%) e Prefiro não informar (1\%). As faixas etárias variam bastante, com a maior concentação entre 18 e 35 anos, assim distribuídos: 18-20, 13\%; 21-25, 22\%; 26-30, 19\%; 31-35, 16\%.

Ao serem perguntadas sobre como fazem contato com outras pessoas, $35 \%$ responderam que utilizam sites específicos para fetiches, enquanto $26 \%$ disseram ir a festas fetichistas e outros $16 \%$ a clubes fetichistas.

Gráfico 1 - Como você faz contato com outras pessoas interessadas em fetiches?

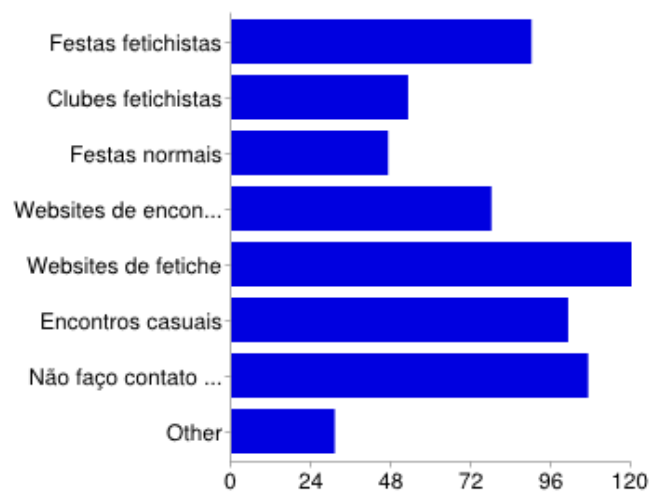

A etapa seguinte do estudo, versou sobre o uso websites de redes sociais e os elementos da construção de identidade. Foi elaborado um segundo questionário online, desta vez enviado somente para as 191 pessoas (56\% do total de 340 respondentes) que responderam que desejavam participar das etapas seguintes do estudo. O link foi enviado por e-mail, com um texto que relembrava o motivo do estudo, explicava o objetivo do questionário.

O questionário online era composto por questões fechadas (idade, gênero e orientação sexual etc.) e abertas (escolhas de identidade, principalmente sobre o uso ou não de pseudônimo, o uso de imagens e descrição de perfil, entre outras). Assumiu-se que estes são os principais elementos para a criação de uma identidade em websites de redes sociais.

Foram sido recebidas 33 respostas em um período de 24 horas desde o envio dos e-mails. Dos 191 e-mails enviados houve quatro ocorrências de erro, as quais foram corrigidas por serem falhas de digitação na entrada dos dados no primeiro questionário online. 
17 dos respondentes (52\%) eram residentes em São Paulo, 9 respondentes (27\%) não eram residentes do Brasil. A faixa etária variou de 20 a 49 anos, com maior concentração entre 26 e 40 anos. 16 identificam-se com gênero masculino (48\%), e outros 16 com gênero feminino (48\%). Um respondente identificou-se como trânsgênero.

Maior variação foi obtida ao responderem sobre suas orientações sexuais

Gráfico 2 - Com qual ORIENTAÇÃO SEXUAL você mais se identifica?

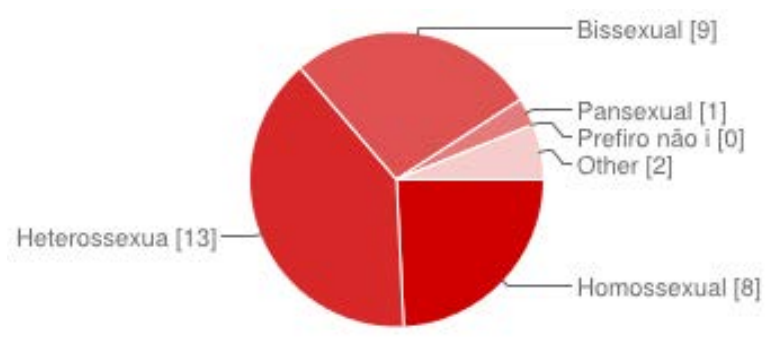

A maioria dos respondentes (18 respostas) afirma ter mais de três anos de prática. Isto reflete, em certa medida, conhecimento das pessoas que se dispuseram a colaborar com o estudo, em suas etapas futuras, como informantes qualificados para participar das entrevistas.

Ao responderem sobre seus papéis, verifica-se que grande parte dos respondentes declararam assumir papéis de submissão ou escrava(o), conforme a tabela a seguir. Vale destacar que a resposta permitia múltiplas respostas.

Tabela 1 - Com qual das opções abaixo MAIS SE ADEQUAM a seus papéis?

\begin{tabular}{|l|r|r|}
\hline Dom/Domme & 5 & $15 \%$ \\
\hline Submissa/Submisso & $\mathbf{1 7}$ & $\mathbf{5 2 \%}$ \\
\hline Mestre/Mistress & 4 & $12 \%$ \\
\hline Escravo/Escrava & $\mathbf{7}$ & $\mathbf{2 1 \%}$ \\
\hline Fetichista & 13 & $39 \%$ \\
\hline Kinkster & 9 & $27 \%$ \\
\hline Switcher & 10 & $30 \%$ \\
\hline Top & 3 & $9 \%$ \\
\hline Bottom & $\mathbf{7}$ & $\mathbf{2 1 \%}$ \\
\hline Sadista & 7 & $21 \%$ \\
\hline Masoquista & $\mathbf{8}$ & $\mathbf{2 4 \%}$ \\
\hline Hedonista & 3 & $9 \%$ \\
\hline
\end{tabular}




\begin{tabular}{|l|r|r|}
\hline Baunilha & 4 & $12 \%$ \\
\hline Insegura(o)/Curiosa(o) & 5 & $15 \%$ \\
\hline
\end{tabular}

Em relação aos elementos que compõem as identidades, 19 respondentes afirmam utilizar pseudônimo, os outros 14 utilizam seus nomes reais.

Dentre as justificativas para a uso de pseudônimo podem-se citar privacidade, discrição e a possibilidade de criar uma identidade alternativa ou paralela.

"Manter minha vida baunilha, familiar e profissional sem interferência de minha vida SM."

"Conheci o fetiche muito nova, adotei pseudônimo por isso. Conforme fui evoluindo e me firmando nisto, passei a me identificar. Uso ainda por questão de costume, mas tenho os mesmos contatos em meu perfil real. Sou autônoma e minha família, inclusive meu marido (que é com quem pratico) tem conhecimento do BDSM em minha vida, desta forma não vejo necessidade do anonimato."

"Identifico-me mais com o meu pseudónimo do que com o nome dado pelos meus pais, uso o meu pseudónimo para tudo e não só para cenas fetiches."

Além da manutenção de privacidade, criar um alter ego e utilizar um pseudônimo pode funcionar como algo mágico, a porta de entrada a um mundo com possibilidades diferentes da vida cotidiana, com regras próprias e também com habitantes que atuam como cúmplices.

"Eu prefiro chamar de AlterEgo. é uma maneira de criar um personagem, uma nova vida, ser o 'deus' daquele ser..."

"Filha do deus Sin da Mesopotâmia, e ao mesmo tempo, filha do pecado."

"Criar um alter ego é muito divertido e complexo também. Eu procuro mostrar o poder máximo de um homem homo através de seus fetiches, sendo eles em seus atos individuais ou em atos combinados entre eles."

"Adotei o nick [REMOVIDO] por amar meus cabelos vermelhos, considero um nome quente, sexy e de bonita pronúncia. Amigos BDSMers ou não dizem que não pareço a mesma pessoa quando não estou ruiva, e que isso reflete melhor minha personalidade."

Apesar de poder haver uma função primária de manter sigilo ou discrição entre possíveis vidas alternativas, a escolha do nome é frequentemente algo pensado com esmero, a fim de refletir alguns aspectos da identidade ou da personalidade do personagem ou do alter ego. Mesmo quando não há uma elaboração deste nível, o pseudônimo passa a ser a maneira de se apresentar e de se fazer conhecer na comunidade.

Com relação ao uso do nome real, as principais justificativas são: não haver motivo para se esconder ou não ter tido oportunidade ou vivência suficientes para adotar um pseudônimo. De qualquer maneira, sustenta-se a tese da identidade relacionada ao nome, e que pode levar tempo, até a pessoa descobrir-se na cena. 
Quanto ao uso de websites de redes sociais, verificou-se que todos os que utilizam, tem perfis no Facebook, com maioria mantendo dois perfis paralelos (19 respostas, 58\%), como ilustrado no gráfico a seguir.

Gráfico 3 - Redes sociais mais utilizadas

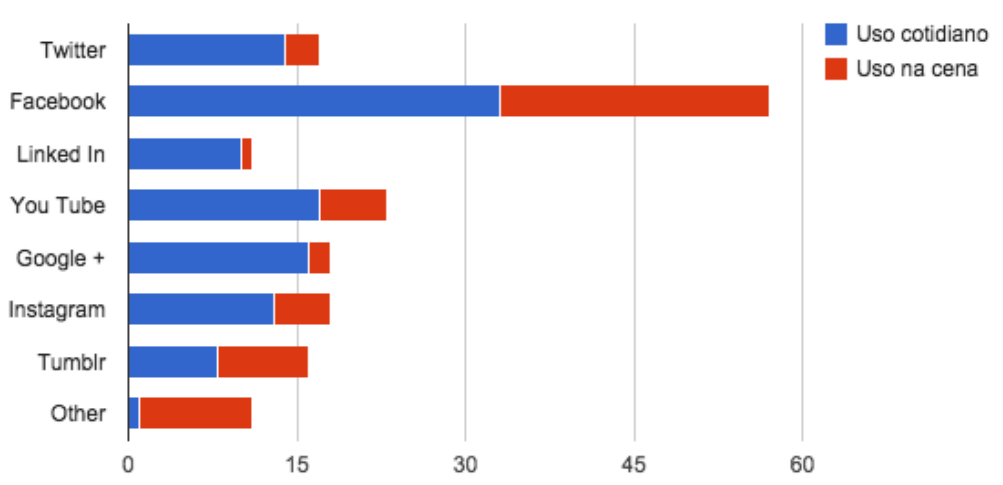

As justificativas mais comuns para a manutencão de perfis duplicados também são sigilo e privacidade, com receio de que colegas de trabalho ou familiares tenham acesso a informações fora da vida cotidiana convencional. No entanto, há o lado da criação de uma realidade paralela, como deixam vislumbrar as declarações a seguir:

"Porque eu considero meu AlterEgo um outro "eu". E sei que meus familiares não aceitariam meus desejos fetichistas revelados."

"Um masculino, profissional, o outro meu lado feminino que amo."

Também há justificativas para a manutenção de um único perfil, seja por não haver referências às atividades fetichistas ou de BDSM, seja pela pessoa possuir uma vida aberta, sem necessidade de ocultar assuntos desta natureza, como ilustra a declaração a seguir.

"Cheguei a criar perfis separados, mas os abandonei. Possuo perfil com pseudônimo nas redes estritamente fetichistas e mantenho um único perfil real no facebook, onde tenho contatos fetichistas e não fetichistas. Mantenho um único por não ser anônima no meio, frequento eventos onde exponho minha identidade real, não vejo necessidade e nem vontade de ter trabalho alimentando dois perfis na mesma rede social."

Com relação ao uso de websites de redes sociais específicos, a plataforma Fetlife foi a mais citada, com 20 respostas (60\%). Esta questão permitia múltipla escolha.

Tabela 2 - Redes sociais mais utilizada

\begin{tabular}{|l|r|}
\hline FetLife & 20 \\
\hline Kinky & 4 \\
\hline Recon & 2 \\
\hline
\end{tabular}


O uso de foto de perfil é um dos aspectos fundamentais na construção de uma identidade em websites de redes sociais. Ao serem questionados sobre o tipo de imagem utilizada em suas fotos de perfil, a maioria (13 pessoas, 39\%) afirmou utilizar foto própria, de rosto, ou foto de partes de seu corpo, ocultando o rosto. A questão permitia múltipla escolha.

Tabela 3 - Que tipos de imagens você utiliza em sua foto de perfil?

\begin{tabular}{|l|r|}
\hline Foto própria, de rosto & 13 \\
\hline Imagem de partes de meu corpo & 13 \\
\hline Foto própria, sem mostrar o rosto & 12 \\
\hline Imagem abstrata & 5 \\
\hline Foto de terceiros, obtida na internet & 4 \\
\hline Imagem de partes de corpo de outra pessoa & 3 \\
\hline Imagem que represente seres fantásticos (dragões, vampiros etc.) & 2 \\
\hline
\end{tabular}

Dentre as razões para escolha de foto de perfis, a maioria dos respondentes confirma que é um elemento de reforço de identidade, mesmo quando não são utilizadas fotos próprias de rosto. As principais razões para não exibir foto de rosto são, novamente, privacidade e sigilo. Já as pessoas com mais tempo na cena, já são conhecidas ou vivem abertamente o estilo de vida e usam fotos de rosto. As falas a seguir servem de exemplo:

"Cada foto de perfil tem o meu interesse pessoal, seja ele sobre mim, sobre algo em particular na sociedade ou noutras pessoas."

"Identificação dos fetiches e dar credibilidade ao perfil."

"Para não correr o risco de algum amigo que, porventura seja fetichista, mas sobre quem desconheço esse lado, venha a me identificar. Mesmo que por uma pequena parte do corpo."

"Por se tratar de um perfil que eu uso pra conhecer futuros amigos ou praticantes, acho justo de saberem quem sou."

Nenhuma razão em especial, no perfil tenho foto própria sem rosto mas nas outras fotos tenho várias com rosto!

"Foto de perfil imagino que seja algo que me identifique, e nada melhor que meu rosto para isso."

Merece ser considerado que os respondentes estão atentos a possíveis perfis falsos e a credibilidade, desta forma é averiguada dentro da própria comunidade. 
Ao responderem sobre o impacto da imagem de perfil, as opiniões variam, mas fica clara a importância de reconhecer e ser reconhecido, seja por um pseudônimo ou sob o nome real.

"Serve como atrativo ou repelente, isso varia de qual imagem e de qual o interesse de quem observa o perfil."

"É a porta de entrada de seu perfil. Seu cartão de visita."

"É a primeira impressão que você dá as pessoas, é o cartão de visita."

"Num primeiro momento serve de filtro para saber se a pessoa é real ou se pode ser um fake. Se não for uma imagem real da pessoa, avalio muito bem para saber se é um fake ou não."

"Saber como é aquela pessoa, fisicamente e emocionalmente. Além de saber se é alguém que não tem vergonha do que curte, e se realmente vive o que diz que gosta ou se apenas fica "no virtual'."

Os elementos principais para a construção de uma identidade em websites de redes sociais são o nome, ou pseudônimo, e a imagem de perfil. Há ainda elementos secundários, como o texto descritivo. Entretanto, pelo apelo visual imediato, é dada maior importância aos dois primeiros elementos.

O pesquisador mantém um perfil de alterego no Facebook, pelo qual mantém contato com os membros da comunidade underground e fetichista no Brasil e no exterior, bem como acompanha eventos e divulga trabalhos. A escolha do pseudônimo teve a função de ser um nome simples, de fácil escrita e memorização. As imagens utilizadas como foto de perfil são de autoria própria ou feitas por fotógrafos, para conferir a noção de apuro estético e de qualidade visual, buscando valorizar o caráter dramático e performático do personagem.

\subsection{Próximos passos}

Incluem entrevistas individuais por Skype ou presencial, dependendo da disponibilidade do respondente. As entrevistas serão semi-estruturadas, em que uma pauta será elaborada, para explorar tópicos de interesse que surjam durante a conversação, em que o respondente é visto como pessoa privilegiada, com conhecimento específico e que poderá falar de suas práticas e de suas identidades.

Para cada entrevista haverá um protocolo de registro por escrito, um termo de consentimento e de uso de imagem. O registro será feito em vídeo, ficando a critério do participante identificar-se com seu pseudônimo ou não, e de revelar seu rosto ou não. As entrevistas versarão sobre o histórico dentro da cena; como escolhe seu visual, o que representa sua imagem; como vê e como é vista/visto pelos demais. Será solicitado uma visita à página de perfil, para que a/o participante fale sobre suas escolhas de fotos, textos e outros elementos de perfil; suas influências e referências. Será pedido consentimento para copiar a tela do perfil com objetivo de ilustrar os relatórios da pesquisa.

Serão ainda realizadas entrevistas com organizadores e produtores de festas e eventos. Procurar-se-á saber o histórico dentro da cena, quais influências e referências; o histórico dos eventos dos quais participa ou organiza/produz; quais os pontos altos e baixos; e quais as pessoas de referência. 


\section{RESULTADOS, DISCUSSÃO E PERSPECTIVAS DA PESQUISA}

Em um trabalho similar, em que estudou o desenvolvimento de interações sociais e identidade em um website de encontros adultos, a pesquisadora Jessica Harding (Harding, 2007) identificou o caráter libertador que se os membros da comunidade sentem ao estarem protegidos por um pseudônimo e poder conversar com diversas pessoas. A autora relata 0 impacto positivo na vida de alguns participantes, em termos de aumento na auto-estima e melhoria em suas relações interpessoais online e offline. Harding também destaca que "A profile is not only a creation of an online identity/persona, but (...) is a personal marketing campaign to sell one's self to the object of one's desire."

Com relação à metodologia escolhida para este estudo, a base é a imersão, ancorada na observação, participativa ou não, de dentro do centro das ocorrências. Certamente que o pesquisador deve possuir conhecimento de técnicas que o auxiliem a identificar tópicos de interesse e recortá-los, a fim de não se ver assoberbado de dados e informações que the impeçam de ver qual caminho seguir. Portanto, é necessário estar aberto ao contexto, porém atento ao que seja relevante para os objetivos do estudo. Isto requer o planejamento das etapas, por meio das quais seja possível ter o panorama global e sucessivamente definir recortes para elaborar relatórios e geração de informações que sejam válidas e úteis.

Trata-se de processo longo, nem sempre adequado aos prazos correntes de projeto praticados no mercado. Para empresas grandes há a possibilidade de recorrer a consultorias ou mesmo criar uma equipe de pesquisa interna, que poderá manter uma linha de investigação focada nos produtos e serviços da companhia e obter achados importantes, mesmo que não imediatamente implementáveis, mas que possam ampliar a visão do negócio a descoberta de oportunidades.

Este artigo tem foco em técnicas qualitativas, no entanto é fundamental considerar a coleta de dados quantitativos, que nos contam quais fenômenos ocorrem, por meio da análise de dados e projeções estatísticas, em um fluxo de trabalho em que haja recorrência na investigação, com foco no entendimento qualitativo e quantitativo da realidade, verificação dos fenômenos, elaboração de hipóteses, validação ou refutação das hipóteses.

\section{REFERÊNCIAS BIBLIOGRÁFICAS}

BARROS, Lydia Gomes de. Subculturas, um conceito em construção. In Anais XXX Congresso Brasileiro de Ciências da Comunicação - Santos - 29 de agosto a 2 de setembro de 2007, Intercom - Sociedade Brasileira de Estudos Interdisciplinares da Comunicação.

BBC News. Facebook has more than 83 million illegitimate accounts Disponível em <http://www.bbc.com/news/technology-19093078> 2 August 2012, Acesso em 17 de janeiro de 2015.

BENNETT, Andy. Subcultures or neo-tribes? Rethinking the relatioship between youth, style and musical taste. In: Sociology Vol. 33 No. 3 August 1999 599-617. 
BLUE, Violet. Facebook nymwars: Disproportionately outing LGBT performers, users furious. In: ZDNet, 12 de setembro de 2014. Online, disponível em <http://www.zdnet.com/article/facebook-nymwarsdisproportionately-outing-lgbt-performers-users-furious/> Acessado em 17 Jan. 2015.

Costa, A. F., A Pesquisa de Terreno em Sociologia. Metodologia das Ciências Sociais, Capítulo V, Lisboa, Edições Afrontamento, 1986.

DENIS, Rafael Cardoso. Design, cultura material e fetichismo dos objetos. In: Arcos, vol. 1, 1998.

GOMES, Rui Telmo - Fazer música Underground: estetização do quotidiano, circuitos juvenis e ritual. Lisboa: ISCTE-IUL, 2013. Tese de doutoramento. Online, disponível em <http://hdl.handle.net/10071/6058> Acesso em 28 Nov. 2014.

HARDING, Jessica. The Development of Social Interactions and Identity Within an Adult Dating, Sex and Swingers Virtual Community: A Case Study of Adult Friend Finder, Social Sciences Journal: v. 7: Iss 1, 2007. Online, disponível em http://repository.wcsu.edu/ssj/vol7/iss1/16.

KIPPER, H.A., A Happy house in a black planet: introdução à subcultura gótica. São Paulo, 2008. Online, disponível em http://www.gothicstation.com.br/Coluna\%20Kipper/Indice\%20Livro.htm.

MAUSS, Marcel. Manual de etnografia. trad. de J. Freitas e Silva. 1. ed. Lisboa : Dom Quixote, 1993. MAFFESOLI, M. The Time of the Tribes: The Decline of Individualism in Mass Society. London: Sage, 1996.

NÓBREGA, Lívia de Pádua. A construção de identidades nas redes sociais, In: Fragmentos da cultura. Goiânia, v. 20, n. 1/2, p. 95-102, jan./fev. 2010.

OGAS, Ogi. Fetishes Do Not Exist (Part II): How clinical and popular conceptions of paraphilias are fundamentally wrong. In: Psychology today, 31 de maio de 2012. Online, disponível em <http://www.psychologytoday.com/blog/billion-wicked-thoughts/201205/fetishes-do-not-exist-part-ii> Acessado em 15 de dezembro de 2014.

PAIS, José Machado, BLASS, Leila Maria. Tribos urbanas: produção artística e identidades. Lisboa : Imprensa de Ciências Sociais, 2004.

PEARSON, Erika. All the World Wide Web's a stage: The performance of identity in online social networks.' First Monday, Volume 14, Number 3 - 2 March 2009. Online, disponível em <http://firstmonday.org/article/view/2162/2127> Acessado em 18 de janeiro de 2015.

SIQUEIRA, Paula. "Ser afetado", de Jeanne Favret-Saada. Cadernos de Campo (São Paulo, 1991), Brasil, v. 13, n. 13, p. 155-161, mar. 2005. ISSN 2316-9133. Disponível em: <http://revistas.usp.br/cadernosdecampo/article/view/50263>. Acesso em: 01 Dez. 2014.

VOLLI, Ugo. Fascínio : fetichismo e outras idolatrias. trad. Miguel Serras Pereira, Lisboa: Fim de Século, 2006 